\title{
НОВЫЕ СЛОЖНЫЕ СЛОВА В АНГЛИЙСКОМ ЯЗЫКЕ
}

\section{NEW ENGLISH COMPOUND WORDS \\ E. Efremova}

Summary: The present article is devoted to the complex investigation of the structural and semantic diversity of English compounds registered in Oxford Advanced Learner's Dictionary during 2020-2021 years. The author determines the part of speech of compound words, shows that they are not homogeneous in their structure, as well as analyses their meaning and thematic group. In the end the author of the article comes to the conclusion that composition is the most productive type of word building in present-day English. On the one hand, such tendency can be explained by the easiness of creating new words from lexical units already existing in the language. On the other hand, compound words specify already existing notions and also determine new notions and objects of the reality.

Keywords: word building, composition, compound word, multi-word compound, linguistic analysis, word building model

\author{
Ефремова Екатерина Михайловна \\ К.филол.н., дочент, Московский педагогический \\ государственный университет \\ Ecatherine1@yandex.ru
}

Аннотация: Статья посвящена комплексному исследованию структурносемантических особенностей новых сложных слов в английском языке, зафиксированных в Oxford Advanced Learner's Dictionary в период 2020-2021 гг. Анализируется частеречная принадлежность, составность, структура, семантика, а также принадлежность отобранных лексических единиц к одной из тематических групп. В результате проведённого исследования автор статьи приходит к выводу, что словосложение является наиболее продуктивным способом словообразования в современном английском языке. Подобная тенденция, с одной стороны, может быть объяснена простотой образования новых слов из уже существующих лексических единиц в языке. С другой стороны, сложные слова уточняют и конкретизируют уже известные понятия, а также служат для обозначения новых понятий и объектов действительности.

Ключевые слова: словообразование, словосложение, сложное слово, многокомпонентный композит, лингвистический анализ, словообразовательная модель.

поисковую систему на новостном сайте ВВС [4].

Лингвистический анализ отобранного языкового материала показал, что с точки зрения частеречной принадлежности сложные слова являются:

- существительными (103 единицы). Например, contact tracer (n) / человек, чья работа состоит в определении круга лиц, недавно контактирующих с больным.

E.g.: "Contact tracers in Scotland will prioritise cases where there is a "high risk" of transmission, as soaring Covid rates put pressure on the system."

- прилагательными (22 единицы). Например, socially distanced (adj) / соблюдающий социальную дистанцию с другими людьми с целью предотвращения распространения инфекции.

E.g.: "The Deer Shed festival will still be socially-distanced as it was last year."

- глаголами (5 единиц). Например, live-tweet (v) / отправлять сообщения о происходящем событии в режиме реального времени с помощью социальной сети Twitter.

E.g.:"A hospital in Nigeria has live-tweeted an operation to repair a hole in the heart of an eight-year-old girl."

С точки зрения составности были выделены: двухкомпонетные композиты (119 единиц) и многокомпонентные композиты (11 единиц).

Под термином «двухкомпонентный композит» мы понимаем сложное слово, состоящее из двух основ-ком- 
понентов. Основа-компонент может быть представлен как полнозначной единицей (непроизводной или производной), так и полуаффиксом. Например, panic buying (n) / покупка большого количества товаров и продуктов повседневного спроса впрок, из-за опасения дефицита или роста цены.

E.g.: "Food industry bodies have warned of panic-buying this Christmas unless action is taken to address labour shortages."

Под термином «многокомпонентный композит» (multi-word compound) мы понимаем, вслед за В.Д. Аракиным, сложное слово, включающее свыше двух основ-компонентов (многоосновное сложное слово В терминологии А.И. Смирницкого) [5; 6]. Отобранные композиты могут быть как трёхкомпонентными (8 единиц), так и четырёхкомпонентными (3 единицы). Например, personal protective equipment (n) / защитная одежда или снаряжение.

E.g.: "Conor McGregor has pledged one million euros worth of personal protective equipment for hospitals in Ireland."

Ещё один пример, high-intensity interval training (n) / высокоинтенсивная интервальная тренировка, включающая физически тяжёлые упражнения и в перерывах между ними более простые упражнения. E.g.: "Although it has been around for a while, high-intensity interval training could be one of this year's biggest fitness trends."

С точки зрения структуры ведущими словообразовательными моделями, характерными для новых сложных слов, являются:

Noun + Noun = Noun (55 единиц). Например, flash sale (n) / внезапная распродажа.

E.g.: "But it has emerged that each flash sale involved only two or three phones and Xiaomi had set its website to say: "Sold out," as soon as the sale opened."

Adjective + Noun = Noun (30 единиц). Например, clinical trial (n) / клинические испытания.

E.g. "The preliminary results of a clinical trial suggest a new treatment for Covid-19 reduces the number of patients needing intensive care, according to the UK company that developed it."

Noun + Adjective $=$ Adjective (7 единиц). Например, life-changing (adj) / изменяющий жизнь к лучшему или худшему.

E.g.: "The driver of one of two trains involved in a crash has suffered injuries believed to be "life-changing", police have said."

Настоящее исследование позволило выявить также словообразовательные модели, не отличающиеся частотностью своей воспроизводимости, однако представляющие интерес с лингвистической точки зрения в силу создаваемого эффекта новизны:
Verb + Verb = Noun. Например, click and collect (n) / Интернет заказ с самовывозом из магазина или пункта выдачи товаров.

E.g.: "Non-essential retailers have been told to close except for click and collect service."

Pronoun + Noun = Noun. Например, YouTuber (n) / видеоблогер, активный пользователь хостинга YouTube.

E.g.: "Indian police have arrested a YouTuber for tying helium balloons to his pet dog "in an attempt to make it fly."

В плане словообразовательного статуса компонентов в ряду отобранных сложных слов выделены:

- сложные слова с полуаффиксом в качестве одной из основ: Ironman (n) / соревнования по триатлону. E.g.: "A Londonderry man who completed 10 Ironman triathlons in 10 days is to be awarded the freedom of the city."

- сложные слова, состоящие из непроизводных основ-компонентов, материально совпадающих с самостоятельно функционирующими лексическими единицами: hand gel (n) / антибактериальный гель для рук.

E.g.:"When he was 19 and lockdown had just started, he developed an idea for a card that snaps to release anti-viral hand gel."

- сложные слова, имеющие в составе производную основу-компонент: spoiler alert (n) / предупреждение о спойлерах (преждевременно раскрытая важная информация, которая портит впечатление от художественного произведения, разрушая интригу).

E.g.: "Martina told me a massive secret that happens in the book, and she forgot to say 'spoiler alert!' I'm so annoyed with her!"

- сложные слова с сокращением в качестве одной из основ: $\boldsymbol{R}$ number (n) / число заразившихся от одного и того же заболевшего (образовано от reproduction number // репродуктивное число).

E.g. "But if the R number is lower the disease will eventually stop spreading, because not enough new people are being infected to sustain the outbreak."

Известно, что одной из основных функций сложных слов в языке является уточнение и дифференциация понятий. Не все отобранные лексические единицы обладают прозрачной семантикой, позволяющей «раскрыть» значение сложного слова, исходя из значений его компонентов. Выявлены сложные слова, которым свойственна та или иная степень идиоматичности. Для таких композитов характерно несовпадение границ номинального и реального денотатов [2]. Семантика таких слов раскрывается не автономно, а через контекст или экстралингвистическое знание естественной логики вещей. Например, английское сложное слово support bubble (n) дословно означает "поддерживающий пузырь", тогда как реальный денотат "встреча с соседями или 
родственниками на дому". С разрешения правительства Великобритании в рамках послабления карантина одиноким людям было разрешено ходить в гости, в какой-то один дом, семью. Однако, нельзя сменить семью, с которой человек вошёл в "сферу поддержки".

E.g.: "Some people across the UK have been able to form household support bubbles or extended households."

Основным значением сложного слова circuit breaker (n) является «выключатель» (автомат для отключения цепей и установок преимущественно в аварийных режимах). В период пандемии на основе метафорического переноса данное слово приобрело ещё одно значение «жёсткий карантин», подразумевающий полное ограничение всех социальных контактов.

E.g.: "Northern Ireland, Singapore and Israel have all used circuit breakers to try to reduce their coronavirus cases."

Стоит отметить, что подавляющие большинство отобранных сложных слов обладает прозрачной семантикой и их значение выводится из суммы значений составляющих их компонентов. Например, farm shop (n) / магазин фермерской продукции.

E.g.: "Footage of a pilot picking up a beef sandwich from a farm shop has been shared online."

Тематическая стратификация отобранной лексики позволяет сделать вывод о том, какие сферы и области жизни были приоритетными для жителей развитых англоязычных стран в 2020-2021 гг.

В период пандемии тема здоровья, здорового образа жизни и красоты стала ведущей. Например, elbow bump (n) / касание локтями в знак приветствия.

E.g.: "The mask-wearing leaders, who met with elbow bumps not handshakes, must also agree a seven-year, $€ 1.07$ tn budget.";

herd immunity (n) / коллективный иммунитет.

E.g.: "Herd immunity is a scientific term describing the point at which a population is protected from a disease, either by enough people being vaccinated or by people having developed antibodies by having the disease.";

patient zero (n) / нулевой пациент, человек, с которого начинается эпидемия.

E.g.: "The study, by the Covid-19 Genomics UK consortium (Cog-UK), completely quashes the idea that a single "patient zero" started the whole UK outbreak.";

self-isolation (n) / самоизоляция.

E.g.: "They overwhelmingly backed the return of mandatory masks in England, and legal self-isolation for contacts of suspected Omicron cases."

Сложно переоценить роль современных телекомму- никационных средств связи в период пандемии. Большая часть нашей жизни из "offline" перешла в "online". Проблема цифровой безопасности никогда прежде не была так актуальна. Рассмотрим несколько примеров: internet of things (n) / интернет вещей, система интернетуправления приборами.

E.g.: "The Internet of Things promised to revolutionise the way we live and work, but has it delivered?";

passcode (n) / цифровой пароль.

E.g.: "Was there a danger that I would be forced by border officials to unlock my phone or hand over my social media passwords?";

friend request (n) / запрос на добавление в друзья в социальной сети.

E.g.: "Can a Facebook friend request be 'harassment'?"

Остро звучит тема взаимодействия людей в семье и обществе, проблема так называемого «третьего пола». Словарь включает, например, следующие сложные слова: cancel culture (n) / культура исключения, публичное бойкотирование человека и его деятельности за высказывание им оскорбительных и дискриминационных взглядов.

E.g.: "What is the cost of 'cancel culture'?"

gender expression (n) / гендерное самовыражение.

E.g.: "Ms Stern said the new gender designation should reduce the "dehumanizing" harassment and mistreatment that so often happens at border crossings when a person's legal documentation does not correspond with their gender expression";

third gender (n) /третий пол.

E.g.: "More than 10 countries, including Canada, Germany, Australia and India, already offer a third gender on documents.";

gender-fluid (adj) / сексуально-изменчивый.

E.g.: "Gender-fluid: Applies to a person whose gender identity changes over time.";

genderqueer (adj) / «особый пол», гендерная идентичность, отличная от мужской и женской.

E.g. "They figured they were a "tomboy" until the age of 16 , but later began to identify as "genderqueer.";

preferred pronoun (n) / предпочтительное местоимение, как правило речь идёт о he (для лиц мужского пола), she (для лиц женского пола), they (для тех, кто не относит себя ни к одному из двух традиционных полов).

E.g.: "A handful of universities go further and allow students to register their preferred pronouns in the university computer systems - and also a preferred name."

Проведённое исследование показало, что словос- 
ложение является наиболее продуктивным способом словообразования в современном английском языке. Структурное разнообразие новых сложных слов является не только средством компрессии, но и свидетельством усиления аналитических тенденций в английском языке. Подобное явление, с одной стороны, может быть объяснено простотой образования новых слов из уже существующих в языке лексических единиц. С другой стороны, в связи с усложнениями и усовершенствованиями во всех сферах жизни современного общества однословных единиц становится недостаточно для наименования денотата. Путём словосложения появляются новые лексические единицы, выполняющие не только номинативную, но и характеризующую, а подчас и экспрессивную функции в языке.

\section{ЛИТЕРАТУРА}

1. Oxford Advanced Learner`s Dictionary. URL.: https://www.oxfordlearnersdictionaries.com/ (дата обращения: 07.12.2021).

2. Ефремова Е.М. Структурно-семантические и функциональные особенности многокомпонентных композитов в современном английском языке: Автореф.дис....канд.филол.наук:10.02.04 [Текст]/Е.М. Ефремова. - Москва, 2012. - 19 с.

3. Лингвистический энциклопедический словарь / гл. ред. В.Н. Ярцева. - 2-е изд., доп. - М.: Большая рос. энцикл., 2002. - 709 c. URL.: https://rus-lingvistdict.slovaronline.com/ (дата обращения: 07.12.2021).

4. BBC NEWS. URL.: https://www.bbc.com/news (дата обращения: 07.12.2021).

5. Аракин В.Д. Сравнительная типология английского и русского языков [Текст] / В.Д. Аракин / Под ред. М.Д. Резвецовой. - 4-е изд. - М.: ФИЗМАТЛИТ, 2008. -232 c.

6. Смирницкий А.И. Лексикология английского языка [Текст] / А.И. Смирницкий. - М.: Изд-во литературы на иностранных языках, 1956. - 260 с.

с Ефремова Екатерина Михайловна (Ecatherine1@yandex.ru).

Журнал «Современная наука: актуальные проблемы теории и практики»

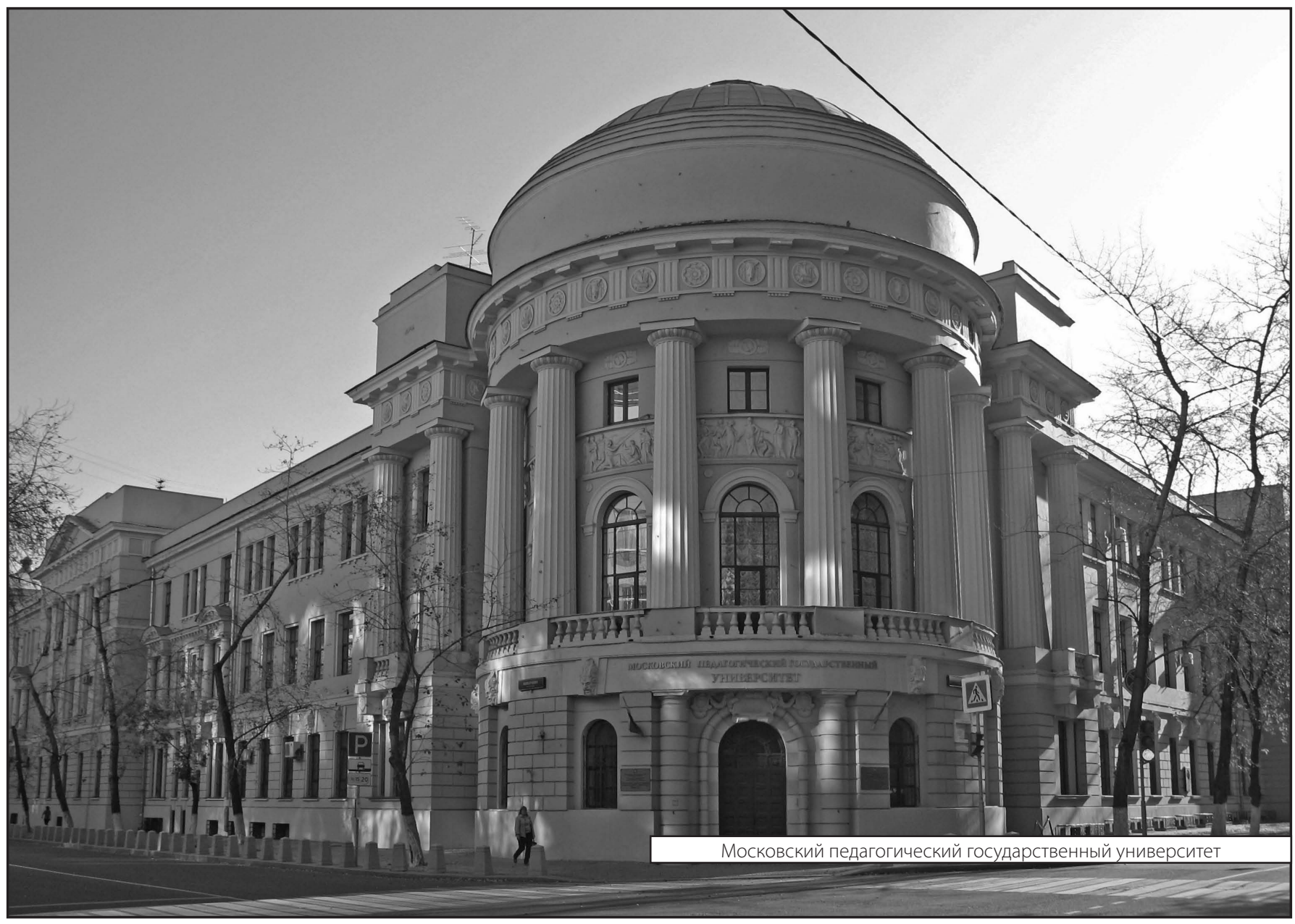

